https://www.journal-imab-bg.org

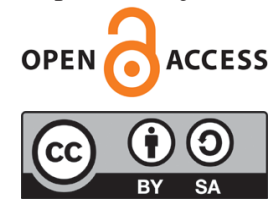

Original article

\title{
EVALUATION OF AN ELECTRONIC PERIODON- TAL PROBE VERSUS A MANUAL PROBE IN THE PERIODONTAL DIAGNOSIS OF CHILDREN AGED 12-14 YEARS
}

\author{
Hristina Tankova, Zornitsa Lazarova, Maya Rashkova \\ Department of Pediatric Dentistry, Faculty of dental medicine, Medical Uni- \\ versity - Sofia, Bulgaria.
}

\section{SUMMARY}

Objective: The purpose of the trial is to comparatively analyze an electronic, pressure-calibrated probe third generation Parometer (Orange) and a standard, manual measurement probe WHO 621 (C type) in the context of taking periodontal variables when assessing periodontal status in childhood.

Materials and methods: The subject of the study were 28 children aged between 12 and 14 years (12 boys and 16 girls). All patients were clinically examined, and the data were recorded on a specially prepared card. The recorded clinical variables contain: Assessment of oral hygiene habits (type of toothbrush, frequency of brushing); OHI as per Green Vermillion; Registration of dental status; Depth of gingival sulcus (on all teeth) with both types of probes; BOP (bleeding on probing), percentage of bleeding units with both types of probes; Taking into account the complete time needed to take the findings and the sensation of pain experienced by a digital rank scale during probing.

Results and conclusion: The average depth of gingival sulcus measured with a mechanical periodontal probe was $1.62 \mathrm{~mm}$, and with an electronic one $-1.38 \mathrm{~mm}$ $(\mathrm{p}<0.05)$. Values for BOP with both types of probes showed an average of $0.30 \pm 0.29$, which is $30 \%$ of all bleeding units examined $(\mathrm{p}>0.05)$. The time for recording the periodontal indices with both probes is, on average, 10 minutes. In both probes, the discomfort of about grade 4 was observed according to the ranking scale used to read sensitivity $(\mathrm{p}<0.05)$. There is a more pronounced sensitivity when using an electronic periodontal probe.

Keywords: Gingivitis, gingival sulcus, periodontal indices

\section{INTRODUCTION}

Periodontal pathology in children 12-14 years of age depends on the dynamics of periodontal status associated with the dental eruption, as well as on the oral hygiene habits of children during puberty [1]. Assessing the condition of the periodontium in childhood is a priority for pediatric dentists in order to prevent the early onset or aggravation of gingival inflammation. The golden standard in assessing the risk of periodontal diseases and recording periodontal status is periodontal probing, the improper performance of which is defined as one of the ten most common causes of failure in dental practice [2]. These errors can be the result of the type of probe used, the accuracy of the reading, the angulation of the probe itself, anatomical variations in the condition of the gingival structures themselves, the presence of inflammation, as well as errors in the transfer of the results and the operator's experience.

Pihlstrom [3] classifies the probes into 3 generations: 1st generation: conventional manual probes; II generation: probes with controlled constant pressure force; 3rd generation: computer-associated constant pressure probes.

Studies show that electronic probes measure the anatomical base of the periodontal pocket, which is why the data obtained exceed those obtained with first-generation probes by an average of $1.58 \mathrm{~mm}$ [4]. The main disadvantage of these probes is the lack of tactile sensitivity during the assessment.

The main challenge when working with children is their fear, mainly related to pain, which is associated with visits to dental offices. In this regard, the assessment of the duration and discomfort during probing is an important factor contributing to building trust and cooperation with adolescents. Sensitivity during probing varies according to the group of teeth being examined, with the upper incisors being the most sensitive in probing, while in molars, it is significantly lower [5,6].

Another challenge when working with adolescents is the lack of sufficient patience required to perform accurate periodontal diagnostics. Reducing the time to assess periodontal status is essential for both clinicians and young patients.

\section{AIM}

A comparative analysis of the assessment of periodontal status in childhood with two methods of probing - with electronic periodontal probe third generation Parometer (Orange) and standard mechanical periodontal probe WHO 621 (type C). 


\section{MATERIAL AND METHODS}

The subject of the study were 28 children aged between 12 and 14 years (12 boys and 16 girls), selected according to the following criteria

- Absence of systemic risk factors for periodontal pathology.

- BOP over $10 \%$ of bleeding units;

- A completed informed consent form of both parents to participate in the research approved by the Research Ethics Committee with protocol No.12 / 14.05.2020;

\section{Methodology}

All patients were clinically examined, and the data were recorded on a specially prepared card. The clinical study was performed in a dental office according to the 4 levels for assessment of periodontal status and risk of periodontal pathology, accepted in the department PDMFDM-MU Sofia, taking into account the duration of the process of establishing periodontal indices and assessment of subjective sensation of discomfort during probing.

The following were performed on each child: first level: lack of anamnestic data for risk of periodontal pathology and assessment of oral hygiene habits (type of toothbrush, frequency of brushing); second level: OHI per
Green Vermillion; third level: registration of dental status, presence of orthodontic anomalies and other existing risk factors; fourth level: depth of gingival sulcus (on all teeth) with both types of probes; BOP (bleeding on probing), percentage of bleeding units with both types of probes;

The study was conducted by one examiner in two visits for each child. An electronic probe study (Parometer) was performed on the first visit. The next day, the child was examined again by performing an identical examination using a mechanical periodontal probe.

\section{Probing methodology}

The method of examination of gingival sulcus depth includes probing all completely erupted permanent teeth at four points: distovestibular, vestibular, mediovestibular and lingual. From the obtained results, the arithmetic means value for each tooth is calculated. Gingival inflammation is objectified by examining provoked gingival bleeding (BOP index) at the same points, calculating the percentage of bleeding units (points) of all probed units.

\section{First visit}

The measurement of the depth of the gingival sulcus at the first visit was performed using a third-generation electronic probe Parometer (Orange) (Fig. 1).

Fig. 1. Electronic periodontal probe Parometer (Orange) and specialized software

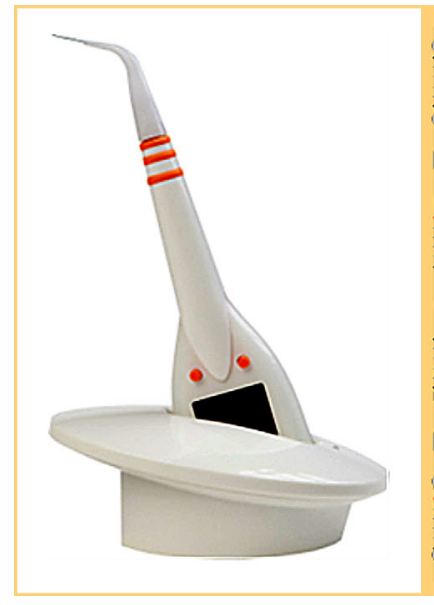

The electronic probe has a display on which the number of the examined tooth, the probing point and the measured depth of the gingival sulcus in $\mathrm{mm}$ are visualized. Each probing is accompanied by an audible alarm announcing the data displayed on the screen. The probe has an elastic tip that ends with a ball on top (diameter of the ball $0.5 \mathrm{~mm}$ ). At the end of the study, the probe is positioned in its docking station, and the examination data are transferred to the patient's file, and all examined indices are calculated automatically.

\section{Second visit}

A WHO 621 mechanical periodontal probe (type C) was used on the second visit to perform the same study.

The probe has the following characteristics: It is graduated at intervals in the direction from the top 3.5,
2.0, 3.0, 3.0 and has a total length of $11.5 \mathrm{~mm}$; The working tip has a ball with a diameter of $0.5 \mathrm{~mm}$; The tip of the probe is rigid; The probe has a color coding between 3.5 and $5.5 \mathrm{~mm}$;

The use of a mechanical periodontal probe involves reading the same probing points to determine gingival sulcus depth and provoked bleeding. The data is registered with the help of a dental assistant, who records it on the patient's card.

Methodology for assessment of discomfort and duration of probing

The measurement of the sensation of discomfort during probing was performed using a digital scale from 0 to 10 , where 0 is no pain, 5 is moderate pain, and 10 is very severe pain [7]. 
A stopwatch from a mobile application was used to estimate the duration of the procedure. The application was started immediately before determining the depth of the gingival sulcus and stopped after entering the data on provoked bleeding of all examined teeth.

SPSS Windows, version 19.0, was used for statistical data processing.

\section{RESULTS}

1. Dental status (DMF $-\mathrm{T}+\mathrm{t}$ ) and oral hygiene of the examined children

The total number of decayed, missed and filled teeth in all 28 examined children was 176 . Of these, $41 \%$ (72) were carious lesions, and the remaining 59\% (104) were fillings. The average number of teeth affected by caries in the examined children DMF $(\mathrm{T}+\mathrm{t})$ is 6 teeth per child.

The following table presents the oral - hygienic status of the children (Table 1)

Table 1. Distribution of mean value of oral hygiene index and frequency of brushing according to age

\begin{tabular}{|c|c|c|c|c|c|c|}
\hline \multirow[b]{3}{*}{ Age } & \multirow{3}{*}{$\begin{array}{c}N \\
\text { child }\end{array}$} & $\mathrm{OHI}$ & & equen & brush & \\
\hline & & \multirow{2}{*}{ Mean $\pm \mathrm{SD}$} & \multicolumn{2}{|c|}{ Twice a day } & \multicolumn{2}{|c|}{ Only in the morning } \\
\hline & & & $\mathrm{n}$ & $\%$ & $\mathrm{n}$ & $\%$ \\
\hline 12 years old & 10 & $1,29 \pm 0,28$ & 4 & 40 & 6 & 60 \\
\hline 13 years old & 12 & $1,19 \pm 0,35$ & 8 & 66,7 & 4 & 33,3 \\
\hline 14 years old & 6 & $1,11 \pm 0,17$ & 6 & 100 & 0 & 0 \\
\hline Total & 28 & $1,21 \pm 0,29$ & 18 & 64,3 & 10 & 35,7 \\
\hline ANOVA & & $\mathrm{T}=0.767 \mathrm{p}=0.475$ & & $\begin{array}{r}\text { gency } \\
\text { Si }\end{array}$ & $\begin{array}{l}\text { ficient } \\
052\end{array}$ & \\
\hline
\end{tabular}

The table shows that the average value of $\mathrm{OHI}$ is 1.21 , which shows satisfactory oral hygiene. There is a tendency for the values of the index to decrease with age, with the highest value being found in 12-year-olds with a progressive decrease in 13- and 14-year-olds. Oral hygiene habits show that about $1 / 3$ of children brush their teeth only in the morning, and the remaining $2 / 3$ twice a day.
The table shows that with age, the percentage of children applying their oral hygiene habits twice a day increases.

\section{Depth of gingival sulcus with a mechanical and} electronic periodontal probe

The following table shows the average value of gingival sulcus depth measured with a mechanical and an electronic periodontal probe (Table 2).

Table 2. Mean depth of gingival sulcus according to the probe used

\begin{tabular}{|l|c|c|c|}
\hline \multirow{2}{*}{ Type of probe } & $\begin{array}{c}N \\
\text { teeth }\end{array}$ & $\begin{array}{c}\text { Mean } \pm \text { SD } \\
\mathrm{mm}\end{array}$ & \multicolumn{2}{|c|}{ Paired Samples Test } \\
\cline { 1 - 2 } Mechanical probe & 784 & $1.622 \pm 0.510$ & \multirow{2}{*}{$\mathrm{T}=13.004 \quad \mathrm{p}<0.05$} \\
\hline Electronic probe & 784 & $1.383 \pm 0.546$ & \\
\hline
\end{tabular}

The tables show that the average depth of the gingival sulcus is in the range of $2.0-3.0 \mathrm{~mm}$. in children and adults. Measured with a mechanical periodontal probe, it averaged about $1.62 \mathrm{~mm}$, while the same measurement with an electronic periodontal probe gave values of $1.38 \mathrm{~mm}$, which is approximately $0.25 \mathrm{~mm}$ less than the average probing depth $(\mathrm{p}<0.05)$.
3. Comparative study of provoked gingival bleeding (BOP index) with mechanical and electronic periodontal probes

The following table shows the distribution of bleeding units in provoked gingival bleeding (BOP index) by probing with a mechanical and electronic probe (Table 3).

Table 3. Mean values of bleeding units by BOP index examined with a mechanical and electronic probe

\begin{tabular}{|l|c|c|cc|}
\hline \multirow{2}{*}{ Type of probe } & $\begin{array}{c}N \\
\text { bleeding units }\end{array}$ & $\begin{array}{c}\text { Mean } \pm \text { SD } \\
\text { bleeding units }\end{array}$ & \multicolumn{2}{|c|}{ Paired Samples Test } \\
\cline { 1 - 3 } Mechanical probe & 3136 & $0.29 \pm 0.32$ & T $=-1.794 \quad \mathrm{p}=0.073$ \\
\cline { 1 - 3 } Electronic probe & 3136 & $0.31 \pm 0.27$ & & \\
\hline
\end{tabular}


When probing with a mechanical periodontal probe, the mean value of the bleeding units is $0.29 \pm 0.31$, which is $29 \%$ of all probed points. The mean value of bleeding units by the electronic probe was $0.31 \pm 0.27$, which is $31 \%$ of all examined points ( $\mathrm{p}>0.05)$.
4. Comparative study of the duration of periodontal examination with mechanical and electronic periodontal probes

The following table shows the time required to perform the periodontal examination with the two types of periodontal probes (Table 4).

Table 4. Mean duration of periodontal probing

\begin{tabular}{|l|c|c|}
\hline \multirow{2}{*}{ Type of probe } & $\begin{array}{c}\text { Duration of periodontal } \\
\text { probing in min. }\end{array}$ & \multirow{2}{*}{ Paired Samples Test } \\
\cline { 2 - 2 } & Mean $\pm \mathrm{SD}$ & \multirow{2}{*}{$\mathrm{T}=0.212 \quad \mathrm{p}=0.834$} \\
\hline Mechanical probe & $9.57 \pm 1.874$ & \\
\hline Electronic probe & $9.50 \pm 0.638$ & \\
\hline
\end{tabular}

The table shows that the time for examination of gingival sulcus depth and provoked bleeding with different types of probes is approximately the same and takes about 10 minutes ( $\mathrm{p}>0.05)$.
5. Comparative study of probing discomfort with mechanical and electronic periodontal probes

The following table shows the discomfort experienced by patients during periodontal probing according to the numerical scale used from 0 to 10 (Table 5).

Table 5. Discomfort when probing with mechanical and electronic periodontal probes

\begin{tabular}{|l|c|c|}
\hline \multirow{2}{*}{ Type of probe } & Discomfort when probing & \multirow{2}{*}{ Paired Samples Test } \\
\cline { 2 - 2 } & Mean $\pm \mathrm{SD}$ & \\
\hline Mechanical probe & $3.43 \pm 1.752$ & \multirow{2}{*}{$\mathrm{T}=2.169 \quad \mathrm{p}<0.05$} \\
\hline Electronic probe & $4.07 \pm 1.741$ & \\
\hline
\end{tabular}

The table shows that in both probes, there was discomfort slightly below the average of 5 , which is below the average level according to the ranking scale used to read sensitivity. There was a more pronounced sensitivity when using an electronic periodontal probe with half a unit of the scale of discomfort $(\mathrm{p}<0.05)$.

\section{DISCUSSION}

Early diagnostics of deviations from the norm for periodontal status in children and adolescents is a priority in pediatric periodontology. This requires targeted research and the use of methods that are as accurate as possible in terms of gingival health parameters and minimally invasive as a procedure.

According to our study, the values determining the depth of the gingival sulcus incompletely erupted teeth are close to the values for the norm in adults and are on average about $1.5 \mathrm{~mm}$. These results correlate with those obtained in our previous study on a larger number of cases in connection with the development of clinical criteria for the assessment of periodontitis in children and adolescents [8]. There are other studies in the literature proving that the depth of the gingival sulcus in the course of dental eruption undergoes significant changes, and the periodontium stabilizes well after the teeth are in occlusion $[9,10,11]$.

The comparative analysis between the two types of periodontal probes shows a greater depth of the gingival sulcus when probing with a mechanical probe - over 1.6 $\mathrm{mm}$ compared to an electronic probe $-1.38 \mathrm{~mm}$. Probably the higher values are due to the more voluminous and rigid tip of the mechanical probe, which leads to the more difficult introduction into the gingival sulcus. On the other hand, this could increase the unconscious pressure from the examiner, which results in a correspondingly more aggressive probing. Similar results are cited by other researchers comparing the two types of probes. According to them, the elastic and thin tip of the electronic probe provides a better opportunity to locate the bottom of the gingival sulcus, as well as more accurately follow the curves of the root surface [12]. According to other authors, the values obtained by probing with an electronic probe are considered equivalent to those obtained by probing with a mechanical periodontal probe $[13,14]$.

Provoked gingival bleeding is accepted as the first sign of gingival inflammation by a number of authors [15, $16,17]$. According to the current classification of periodontal diseases, plaque-associated gingivitis is defined as one in which provoked bleeding is detected in more than $10 \%$ of bleeding units. Our study found no differences in the values for provoked bleeding when using different types of probes, and in both cases, there are about $30 \%$ bleeding units in the studied children. Contrary to these results, German authors found that values for provoked bleeding were higher when using a mechanical periodontal probe [12]. Accurate performance of the probing procedure requires approximately 10 minutes for both types of periodontal 
probes according to our study. Other author teams receive similar results [12].

In a comparative study of the two types of probes, we found that the discomfort was moderate, being greater with the use of an electronic periodontal probe. Contrary to these results, other authors have found reduced discomfort when using an electronic probe [12]. Probably this is due to the fear perceptions of children at the sight of the thin tip of the electronic probe.

\section{CONCLUSIONS}

1. The use of a mechanical periodontal probe shows higher values for depth of gingival sulcus- $1.62 \mathrm{~mm}$ com- pared to electronic probe- $1.38 \mathrm{~mm}$.

2. No differences were found between the two types of probes in terms of provoked gingival bleeding.

3 . The time required for conducting the periodontal examination with the two types of probes is identical - 10 minutes.

4. The discomfort of probing is more significant with the use of an electronic periodontal probe.

The publication is under the Grant 2020 project with Contract No. 113 / 24.06.2020. on the topic "Epidemiology, diagnostics, treatment and prevention of plaque-induced gingivitis in childhood and adolescence."

\section{REFERENCES:}

1. Rashkova M. Periodontal diseases in children and adolescents. Sofia: Direct Services; $2016.98 \mathrm{p}$

2. Newman MG, Takei HH, Klokkevold PR, Carranza FA. Carranza's clinical periodontology. 10th ed. St. Louis, Mo.: Saunders Elsevier. 2006. p.550. [Internet]

3. Pihlstrom BL. Measurement of attachment level in clinical trials: probing methods. J Periodontol. 1992 Dec;63(12 Suppl):1072-7. [PubMed]

4. Gibbs CH, Hirschfeld JW, Lee JG, Low SB, Magnusson I, Thousand RR, Yerneni P, Clark WB. Description and clinical evaluation of a new computerized periodontal probe-the Florida probe. J Clin Periodontol. 1988 Feb;15(2):137-44. [PubMed]

5. Canakci V, Canakci CF. Pain levels in patients during periodontal probing and mechanical non-surgical therapy. Clin Oral Investig. 2007 Dec;11(4):377-83. [PubMed]

6. Heins PJ, Karpinia KA, Maruniak JW, Moorhead JE, Gibbs CH. Pain thresh- old values during periodontal probing: assessment of maxillary incisor and molar sites. J Periodontol. 1998 Jul;69(7):812-8. [PubMed]

7. Wong DL, Baker CM. Pain in children: Comparison of assessment scales. Pediatr Nurs. 1988 Jan-Feb;14(1):9-17. [PubMed]

8. Mitova N, Rashkova M, Tankova Hr. [Gingival sulcus depth in healthy children with teeth in eruption.] [in Bulgarian] Problems of dental medicine. 2017; 43(2):79-86.

9. Emmerling H, Standley E. Probing into Probes, Measuring the Choices. CDHA Journal. 2010; 25:15-19.

10. Hefti AF. Periodontal probing. Crit Rev Oral Biol Med. 1997; 8(3):336-56. [PubMed]

11. Weinberg MA, Westphal C, Palat M, Froum S, Schoor R. Comprehensive Periodontics for the Dental Hygienist. 3rd Edition. Prentice Hall. Mar 27, 2010. [Internet]

12. Renatus A, Trentzsch L, Schönfelder A, Schwarzenberger F, Jentsch H. Evaluation of an Electronic Periodontal Probe Ver- sus a Manual Probe. J Clin Diagn Res. 2016 Nov;10(11):ZH03-ZH07. [PubMed]

13. Niederman R. Manual and electronic probes have similar reliability in the measurement of untreated periodontitis. Evid Based Dent. 2009; 10(2):39. [PubMed]

14. Rams TE, Slots J. Comparison of two pressure-sensitive periodontal probes and a manual periodontal probe in shallow and deep pockets. Int J Periodontics Restorative Dent. 1993 Dec;13(6):520-9. [PubMed]

15. Trombelli L, Farina R, Silva CO, Tatakis DN. Plaque-induced gingivitis: Case definition and diagnostic considerations. $J$ Clin Periodontol. 2018 Jun;45 Suppl 20:S44-S67. [PubMed]

16. Mühlemann HR, Son S. Gingival sulcus bleeding - a leading symptom in initial gingivitis. Helv Odontol Acta. 1971 Oct;15(2):107-13. [PubMed]

17. Greenstein G, Caton J, Polson AM. Histologic characteristics associated with bleeding after probing and visual signs of inflammation. J Periodontol. 1981 Aug; 52(8):420-5. [PubMed]

Please cite this article as: Tankova T, Lazarova Z, Rashkova M. Evaluation of an electronic periodontal probe versus a manual probe in the periodontal diagnosis of children aged 12-14 years. J of IMAB. 2021 Oct-Dec;27(4):4087-4091. DOI: https://doi.org/10.5272/jimab.2021274.4087

\section{Address for correspondence:}

Dr. Hristina Ivanova Tankova-Zlateva

Department of Pediatric Dentistry, Faculty of Dental Medicine, MU - Sofia,

1, Georgi Sofiyski Str., Sofia, Bulgaria.

E-mail: la_svetichi@yahoo.com 